\title{
Changes in turn-design over interactional histories - the case of instructions in driving school lessons
}

\section{Arnulf Deppermann}

\begin{abstract}
This paper studies how the turn-design of a highly recurrent type of action changes over time. Based on a corpus of video-recordings of German driving lessons, we consider one type of instructions and analyze how the same instructional action is produced by the same speaker (the instructor) for the same addressee (the student) in consecutive trials of a learning task. We found that instructions become increasingly shorter, indexical and syntactically less complex; interactional sequences become more condensed and activities designed to secure mutual understanding become rarer. This study shows how larger temporal frameworks of interpersonal interactional histories which range beyond the interactional sequence impinge on the recipient-design of turns and the deployment of multimodal resources in situ.
\end{abstract}

Keywords: recipient design, turn-design, interactional histories, driving lessons, conversation analysis

\section{Introduction}

The sensitivity of turn-design to the particular addressee(s) is a basic property of all interactional conduct. One of the main sources of recipient design of turns lies in prior interactional experiences which the speaker shares with their interlocutor(s) as common ground. Shared biographical time thus is a major determinant of the design of interactional practice and the choice of multimodal resources to build actions. Although the enormous relevance of common ground for turn-design is indisputable, we still do not know much about the development of recipient design over interactional histories.

This chapter focuses on one highly recurrent type of joint action in order to track changes in recipient design over time. We consider one type of instructions in driving school and analyze how the same type of instructional action is produced 
by the same speaker (the instructor) for the same addressee (the student) in consecutive trials of a learning task, starting with the very first time the instruction is performed. This study thus is an inquiry into the relationship between larger temporal frameworks of interpersonal interactional histories which range beyond the interactional sequence and interactional events on the one hand and the local choice and deployment of multimodal resources in situ. The aim is to identify patterns of changes of the means of recipient design over time and to understand how they may be rooted in the pragmatics of shared experience. After a short introduction into the three notions which build the theoretical framework of our study, recipient design (Section 2), interactional histories and common ground (Section 3), we introduce the object and the data of our study, instructions in driving lessons (Section 4). The main body of the chapter is devoted to three case studies of changes in recipient design of the same type of instructions over time in driving lessons (Section 5). Section 6 summarizes the findings and adds some quantitative evidence. Section 7 concludes with a discussion of the upshots of this study for our understanding of the relationship between interactional histories, cognition and the design of situated actions in interaction.

\section{Recipient design}

Recipient design is a key notion in the study of social interaction. It concerns the way talk is tailored to its specific addressee: "By 'recipient design' we refer to a multitude of respects in which the talk by a party in a conversation is constructed or designed in ways which display an orientation and sensitivity to the particular other(s) who are co-participants." (Sacks et al. 1974, 727). The term 'recipient design' thus does not simply refer to the basic dialogical other-orientedness of all talk being used for communicative purposes (cf. Linell 2009). 'Recipient design' is more specific (see Deppermann and Schmidt 2016). The term is meant to capture how the specific individual or categorical properties of the intended addressee(s) which the producer of a stretch of talk ascribes to their addressee inform the talk to be produced.

Recipient design relies on and indexes the speaker's partner model. Prior research has supported the relevance of the following aspects of the partner model:

- Speaker's knowledge about recipient's knowledge (Schegloff 1972; Goodwin 1979; Sacks and Schegloff 1979; Clark and Marshall 1981; Clark and WilkesGibbs 1986; Isaacs and Clark 1987; Schegloff 1996),

- Category membership of recipients (Isaacs and Clark 1987; Hutchby 1995; Fischer 2016),

- Speaker's assumptions about recipient's assumptions about speaker's meaning/ attitudes (Deppermann 2014). 
Recipient design is intimately linked to the accomplishment of intersubjectivity in interaction (Deppermann 2015a). It is the addressee-specific particularization of the general idealization of intersubjectivity (in the sense of Schütz 1974[1932], building on Husserl 1995[1929]). Recipient design embodies what the speaker presumes to be intersubjective. By virtue of this property, recipient design is also a resource for other-positioning the addressee as a person with specific properties of understanding, propensities to act, social and personal features, etc. Other-positioning is prospective in projecting an addressee of a certain type. Recipient design presupposes and builds on what a speaker considers to be common ground and on other ascriptions to the recipient which are relevant to their presumable understanding of the speaker's actions. The assumptions informing recipient design may build on a) first-hand knowledge from shared interactional history, i.e. prior experience, with the recipient, b) second-hand knowledge about the recipient via others, c) expectations and stereotypes tied to the assignment of the recipient to a membership category (Sacks 1992). As for shared interactional history as a source of recipient-design, Maynard (1989) and Deppermann and Schmitt (2009) have shown how the recipient design of turns is adapted by checking the recipient's knowledge, expectations and/or self-positioning earlier in the same interactional sequence. Recipient design thus is continuously adapted on the grounds of the ongoing local experience with the addressee, their actions and their responses to the speaker's own prior actions. By virtue of this sensitivity to shared interactional history, the recipient design of turns reflects the emerging relationship between the participants.

In this chapter, we will analyze how this source of recipient design - shared interactional history - accounts for changes in turn design of the same type of routine actions with the same recipient over time. We will thus study how retrospective sources of recipient design, i.e. common experience of past episodes of successful or failed accomplishment of intersubjectivity and task-performance are mobilized for the design of turns at talk in the service of bringing about future intersubjectivity.

\section{Interactional history and the accumulation of common ground}

This chapter studies how recipient design of turns builds on shared interactional histories. By 'interactional history', we refer to previously shared interactional experiences of participants in interaction. Sharing experience does not simply mean to have the same experiences independently, but to exchange experiences and make experiences with each other in a shared situation. Schütz (1971[1945], 219) describes this as the "common vivid present" of a "We-relation". He captures such stretches of shared biographical time by the formula "we grow older together" 
(Schütz 1971[1945], 220). In interactional histories, people do not only get to know each other (their skills, knowledge, expectations, preferences, etc.), they also create common ground by virtue of interacting with each other. Common ground most importantly consists of shared meanings assigned to words (cf. Clark 1996a), phrases and stretches of behavior (action ascription) and of shared expectations about who will perform which kind of a next action given a certain situation, action or linguistic usage. Interactional histories have both a microscopic and a macroscopic dimension. Microscopically, interactional histories develop moment by moment in sequentially organized interactions and in situations of mutual monitoring (in co-presence, but also in mediated interaction). Thus, the accomplishment of intersubjectively shared meaning of an action via a sequence of reciprocal displays of interpretation and maybe negotiation (Sidnell 2014; Deppermann 2015b) is the result of an interactional micro-history. This emerging micro-history lays the ground for next actions building on it, allowing participants to presuppose intersubjectively accomplished meanings and knowledge, i.e. common ground, for ensuing joint action (Clark 1996b). The same applies to interactional histories on a temporally more extended scale, which may range from consecutive interactions of the same participants up to whole biographies which are largely shared by people living closely together.

In such interactional macro-histories, shared experience leads to an accumulation of common ground which is used in future interactions. Besides presupposing common ground, this is evidenced by indexing efficiently the relevance of common ground which has been accomplished earlier (cf. Mondada 2015). Simply presupposing common ground often does not or would not work, if it is not salient to the partner. Common ground has to be indexed in order to be used for interpretation. The enormous relevance of shared interactional history for the way in which actions are performed and turns are formulated is evident, e.g., in the emergence of abbreviations for recurring expressions in working teams and families, in elliptical turn-design or also in "neurotic" reactions in long-standing relationships, where the prior action seems innocent and does not account for an aggressive or irritated response from an outsiders' perspective.

Although the effect of shared interactional history is clearly visible in such cases, the precise ways in which specific experiences lead to specific ways of turn-construction and action-formation remain mostly opaque to the analyst. This is due to the lack of data which provide for a detailed and comprehensive documentation of some interactional history. In the absence of such data, however, it is hard to track in a rigorous manner the ways in which prior shared experiences inform later joint action. A study that aims to arrive at such an understanding has to meet methodological requirements which are not so easy to fulfill (see also Pekarek Doehler et al. 2018): 
- We need a continuous record of the shared interactional history of the participants without gaps in order to be sure to capture all shared experiences which contribute to the emergence of common ground, shared routines, etc.

- We need to have access to recurrent types of interaction sequences (actions, referential practices, rituals, etc.) in order to be able to identify change over time (see, e.g., Berger and Pekarek Doehler 2018). This is because we need a tertium comparationis which allows us to observe how shared experience with instances of an interactional sequence (action, referential practice, ritual, etc.) impinges on and is used (presupposed, re-indexed) on a next occasion when the same type of interactional sequence (action, reference) again is at issue among the same participants. Of course, prior experience will also impinge on future interactional encounters among the same participants in which different interactional tasks and actions are at issue. However, given that we currently know hardly anything about the effects of interactional histories on the recipient design of turns, actions and references, a methodologically more promising and more reliable starting point for analyses will be to be more restrictive and track changes in the performance of the same type of joint action over time.

Until now, studies which meet these requirements fully have only been conducted in experimental settings. Herbert Clark and his confederates have studied changes in recipient design over repeated task-related joint activities using varieties of the so-called 'referential communication task'. These tasks ask a 'matcher' to identify pictures correctly in response to a 'director's' descriptions. It was revealed that over a series of performances of the same tasks by the same participants, matchers' references exhibit an increased economy of linguistic form (Clark and Marshall 1981; Clark and Wilkes-Gibbs 1986; Isaacs and Clark 1987). E.g., descriptions are replaced by names and nominal phrases, definite references supplant indefinite ones, abbreviations are used instead of complex nominal phrases. Overall, turn-length and number of speaker changes per task were found to diminish. However, it was also observed that speakers tend to stick with formulation choices which have proved to be successful for accomplishing mutual understanding in the past (cf. Pickering and Garrod 2004), even if simpler options become available because of contextual changes. Brennan and Clark (1996) term this phenomenon 'conceptual pacts', meaning that participants have come to a shared convention of how to encode a certain joint conceptualization. While these studies have yielded important insights into how the accumulation of common ground over interactional histories informs the recipient-design of future actions, they suffer from the usual limitations of ecological validity which are typical of experimental studies. Subjects were confronted with artificial tasks in a very restricted pragmatic, topical and referential environment, the range of actions which could relevantly be performed was 
unnaturally small, variation of the particulars of the local situation was ruled out by standardization, subjects did not act out participant roles tied to everyday institutional and personal relationships and their associated rights, duties and identities.

The study to be reported in this chapter, on the contrary, meets the requirements for a study on the relevance of shared interactional history for recipient design outlined above, without succumbing to these drawbacks of an experimental approach.

\section{Object of study: Instructions in driving lessons}

In order to study how turn design changes over and by virtue of shared interactional histories, we have tracked the longitudinal development of the design of instructions of the same task in driving lessons. Driving lessons provide a perspicuous setting for this study. They meet the methodological requirements for studying the changes of recipient design during interactional histories which have been laid out in Section 3 in an ideal way for the following reasons:

- Driving lessons are naturalistic experiments: Participants rehearse the same tasks (such as changing gears, turning left at an intersection, reverse parking the car, etc.) over and over again. This allows us to track changes in the design of the same type of action, namely instructions to perform a specific task, over time. Still, these are part of naturally occurring, participant-administered institutional activities without any scientist-induced experimental frame. Rather, the experimental flavor of these episodes arises from the very nature of the social activity and its aims (i.e. bringing the student's skill to perfection by rehearsing).

- Complete interactional histories are available: We have recorded the whole process of the practical instruction from the very beginning, i.e. the first driving lesson, without any gap, for four students. All of the relevant experiences which the participants share with each other concerning the tasks to be considered are available as video-recorded data. The data thus allow us to track the emergence of common ground over repeated task-performances and the adaptation of recipient design by virtue of this shared interactional history.

- The efficacy of recipient design is (mostly) observable: Since (apart from the very first instruction) the student has to comply with instructions immediately, the student's understanding and their acquisition of competence (learning) become public in situ. Thus both the adequacy of the instructor's recipient design and how it is adaptively occasioned by the task-performances of the student can be analyzed by relating it to the ongoing responses of the students. 
In contrast to other participation frameworks such as, for example, friendships or professional teams, changes in the recipient design of instructions over time are closely related to the process of learning: The goal is to "build competent members" (Goodwin 2017), who will finally be able to perform the instructed actions correctly and self-initiatedly whenever they become relevant. Thus, the final goal of the process of instructions is to make instructions unnecessary. As far as learning is concerned, changes in recipient design are tied to the recipient's (gradually increasing) transition from a novice to a fully competent actor, which is reflected in the instructor's action formation (see also Broth et al. 2017).

The data come from a larger corpus of approx. 70 hours of video-recordings from driving lessons with two cameras (passenger view and street view) recorded in 2012-13 in Germany. Among them, approx. 45 hours are recordings of four students $(3 \mathrm{~m}, 1 \mathrm{f})$ with a female instructor which each start with the first lesson. This sub-corpus was inspected for all occurrences of rehearsals of one specific task, reverse parking the car. With three of the students, this task was rehearsed in two series of four to seven runs each $(6+6 ; 5+7 ; 6+4)$; one student (who was more experienced and already held a motorcycle license) had to perform only one rehearsal session with six runs. In total, 40 runs of rehearsing reverse parking have been transcribed according to GAT2 (Selting et al. 2009) and analyzed sequentially and multimodally. All instructions occurring in these 40 runs of rehearsals were coded according to a number of linguistic, gestural, praxeological and interactional variables. All data were coded independently by the author and another coder who also had participated in the sequential data analysis. Differences in coding were checked and discussed, resulting sometimes in refining the guidelines for coding and in consensual attribution of codes in discrepant cases. Quantitative findings of these sample analyses will be reported in Section 6.

The main body of this chapter (Section 5) will provide an in-depth conversation analytic treatment of three cases, which have been transcribed according to GAT2 with additional multimodal transcription according to Mondada (2018). We will analyze changes in the recipient design of instructions of one specific sub-task of the process of reverse parking over the learning process. The sub-task to be considered concerns the issue: How far does the student have to reverse the car into the parking space until s/he has to steer to the left?

Figure 1 shows the relevant landmark which the student has to observe: S/he has to reverse the car until the b-column of the car (i.e. the middle column located between the two right side windows of the car) yields a line with the left rear light of a car parked in front which is in parallel with the sidewalk. 


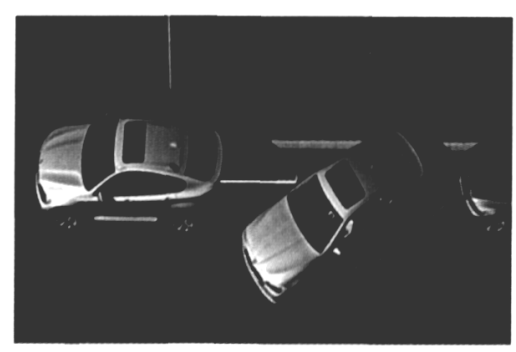

Figure 1. Reversing the car until its b-column yields a line with the left rear light of a car parked in front which is in parallel with the sidewalk

\section{Case analyses of interactional histories: Changes in instructional practice over time}

In this section, we analyze the ways in which the recipient design of instructing the sub-task to reverse the car into the parking space changes over time by virtue of shared interactional histories. Consecutive task performances from three students will be considered. For each student, the very first and the second task-instructions will be analyzed. In addition, two later instructions which exhibit further relevant changes in the design of instructional activity will be discussed for each student.

\subsection{Case 1}

As with all the students in our data, the first instruction is produced while the car is not moving. The instructor demonstrates how the car has to be reversed into the parking space by using a toy car representing the driving school car and a box which represents the car parked in front, which serves as a landmark:

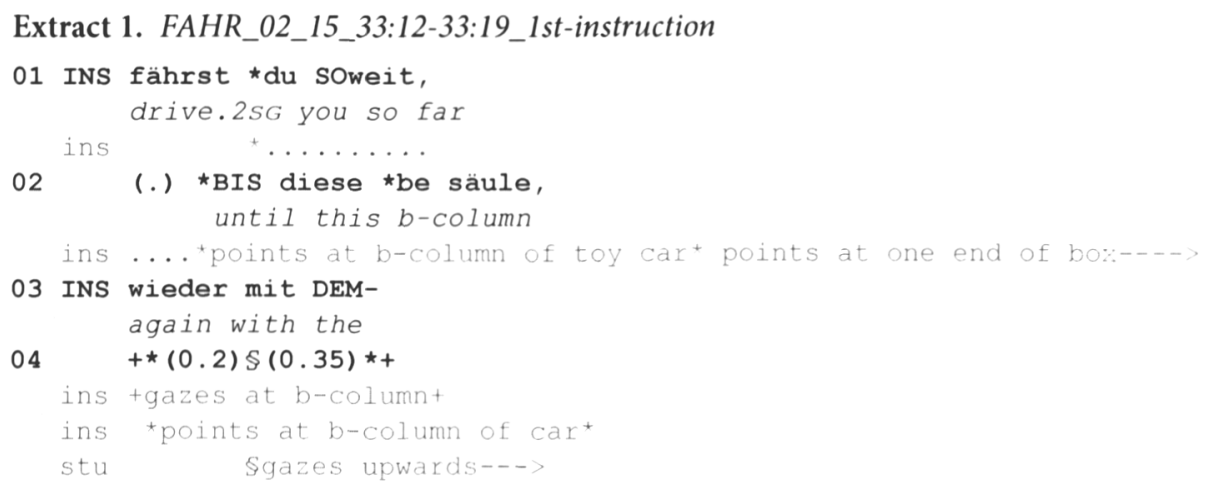


INS +mit dem \$LISCHT so;

with the light like this

ins tgazes at toy car---->

Sgazes at toy car $-\cdots$
INS (0.2) *eine LInie so hier ergibt

makes for a line kind-of here

07 INS SIEH[ST +du ]?

you see?

08 STU [hm_hm; ]

uhum

ins

+gazes at student---->

This first instruction is delivered as a complex description, consisting of a complex sentence including a locative adverbial clause. The main clause exhibits three arguments (agent $=d u$, 'you', 01; location $=$ soweit, 'so far', 01; location $=$ adverbial clause, 02-06), the adverbial clause does so as well (theme = be säule, 'b-column, 02; counter-theme $=$ mit dem lischt, ' with the light', 05; result = linie, 'line', 06). The student should not follow the instruction in situ. The declarative mood of the instruction (as opposed to, e.g., the imperative or the deontic infinitive) is typical of the turn-design of first instructions in driving lessons (see Deppermann 2018). It does not only index that the instruction does not have to be complied with immediately, but it also stresses the descriptive and generalizable content of the instruction, i.e. being an explication of a regular procedure. The action to be performed is explicitly mentioned (fährst du SOweit (.) bis [...], 'you drive so far until [...]') and three landmarks are provided by explicit categorization (be säule, 'b-column', 02;

1. Immediately before this extract, the instructor had defined the term $B$-Säule ('b-column') ostensively by gesturing and verbally by building a paradigmatic contrast with the two other columns of the car:

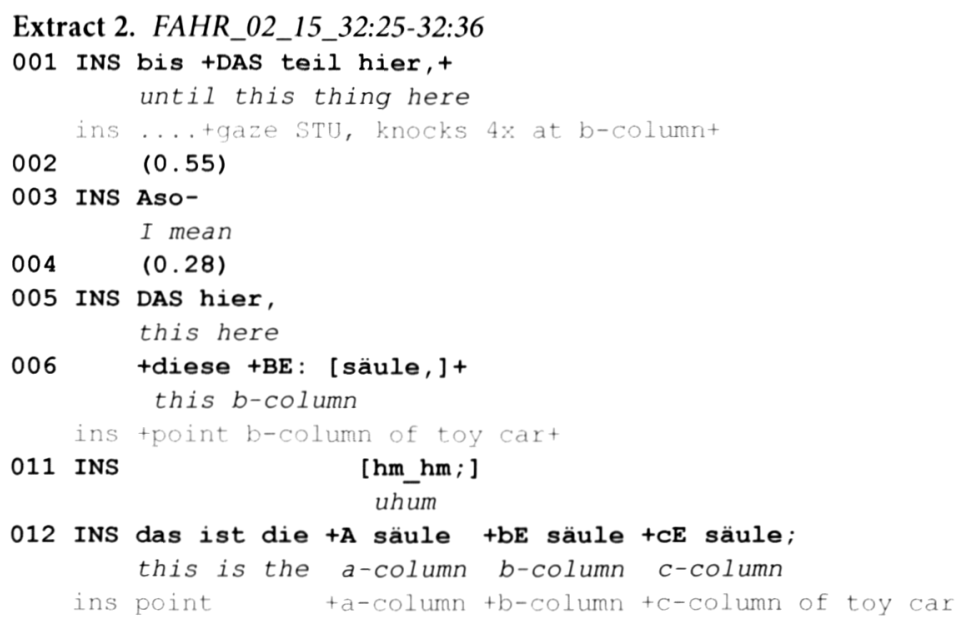


mit dem licht, 'with the light', 05; linie, 'line', 06). Verbal references to landmarks are coordinated with pointing gestures (02: to b-column of toy car, 02 : to rear light of car in front represented by box, 04 : again to b-column of toy car). An iconic gesture finally is produced in sync with the verbal reference to the imaginary line between the b-column of the toy car and the rear light of the other car, until which the car has to advance. The instruction in 01-06 is prosodically segmented into installments (Clark and Brennan 1991; Svennevig 2015), which partition the information into small chunks. The instructor closes the instruction of this step of the procedure of reverse parking with an understanding-check (06) and then monitors the student's understanding display also visually (07-08).

In the second trial of reverse parking, which follows immediately after the first, which has been analyzed above, the student implements the instructed action for the first time. In contrast to the first run, the car is now positioned at the point where the student should start to reverse into the parking space.

Extract 3. FAHR_02_15_34:11-34:24_2nd-instruction

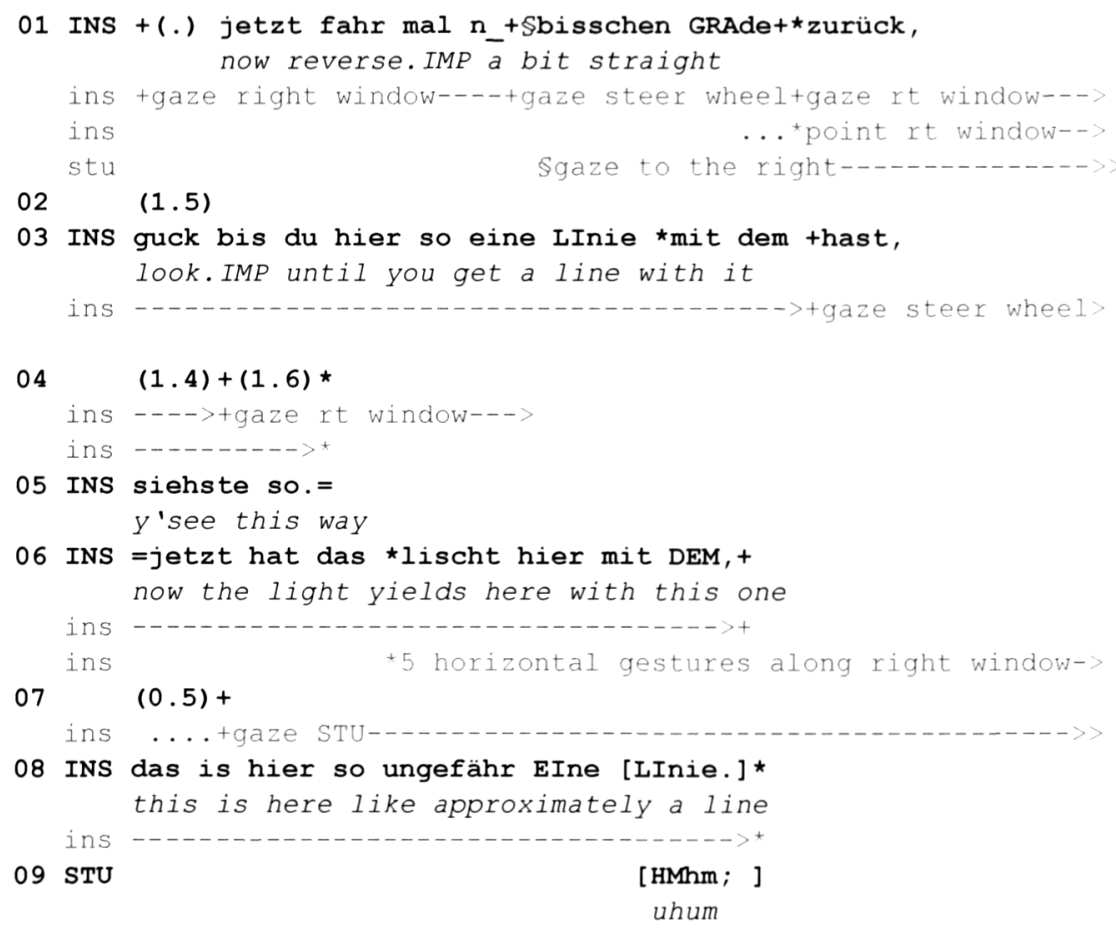

In contrast to the first instruction, the second is delivered in imperative mood, and it is to be followed by the student in situ. The argument structure is less complex than in the first run. The instruction is again produced by a complex sentence including a resultative adverbial phrase. The main clause includes two arguments 
$(01:$ manner $=$ grade, 'straight'; result $=$ adverbial clause $),{ }^{2}$ the adverbial clause has three arguments (03: agent $=d u$, 'you'; result $=$ eine linie, 'a line'; theme $=$ mit $\mathrm{dem}$, 'with it' (= the rear light of the car in front)). In contrast to the first run, the latter reference is not lexical-categorical, but purely deictic, using a pronoun coordinated with a pointing gesture. Equally, the categorical term $b$-column (of the driving school car) now is replaced by the metonymical pronoun $d u$ ('you'). Both pronominal references, which are much less granular and less precise than the references to the landmarks in the first run, index that the student is considered to be able to identify which precise part of the other car and the driving school car should be taken as relevant coordinates for the line which has to be reached. The teacher monitors the student's actions by looking at her manipulation of the steering wheel and, alternatively, observes how the car is moved into the parking space. The instructor draws the student's attention to the fact that they have reached the imaginary line (05-08). In a cut-off TCU, the instructor refers to the rear lights of the car ahead lexically and to the b-column as coordinates gesturally and by a pronoun (or article at the cut-off point - the finite verb form and possibly a noun are missing, 06); she then repairs her formulation, referring verbally to the line by an indefinite NP and indexing its coordinates by hier ('here') and associated iconic gestures (08), now using a copulative construction. The student acknowledges this noticing by an understanding display, which is monitored by the instructor (08-09).

The student fails the following trial, because she went backwards too fast when reversing into the parking space. The following fourth instruction, still in the same lesson, is packaged as a reminder of what the student has to do next.

Extract 4. FAHR_02_15_39:04-39:08_4th-instruction

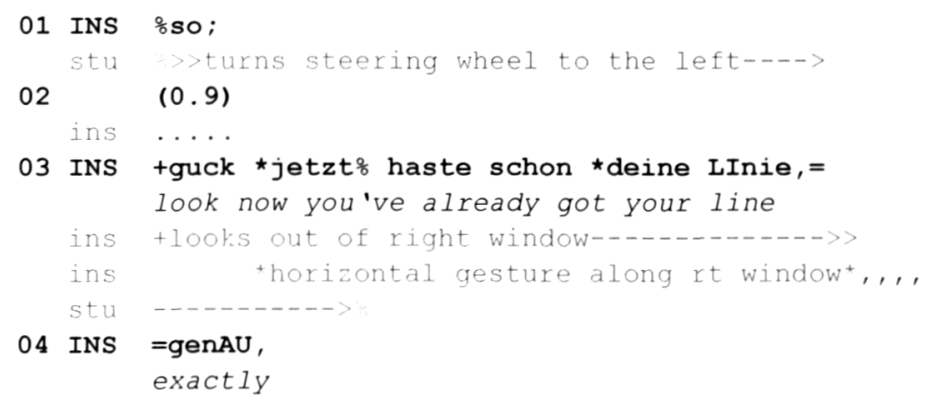

2. One could equally argue that there are three arguments, because "zurück" ('back') may either be considered as an instance of the thematic role 'direction' or as split part of the verb zurückfahren (so-called Verbpartikel, 'verb particle'). In the latter case it is not counted as an argument. 
In this instruction, the teacher uses a less complex grammatical format. It consists only of a simple main clause with two arguments (agent $=d u$, 'you'; result $=$ deine linie, 'your line', 03). The action to be performed is not mentioned anymore, but a light verb (hast, 'have') is used. Its 'achievement'-meaning is provided for by the direct object in the result role. The resulting landmark, the line, is also demonstrated by an iconic gesture. The mention of the landmark is itself action-implicative: It implies that the student has to stop at it (and prepare for turning the steering wheel into the opposite direction). The other landmarks, however, which make for the line (i.e. the b-column, the rear light of the car in front), are not mentioned anymore. This third instruction is much more indexical and shorter than the two earlier instructions: It presupposes actions (driving and stopping, perhaps also steering) and relevant landmarks in order to be understood properly. The instruction could not be understood as a first instruction, it works only as a non-first, consecutive instruction which builds on common ground which has been achieved in previous joint performances of the same task. Most interestingly, the instructor uses the possessive indexical formulation deine linie ('your line') instead of an indefinite $\mathrm{NP}$ in the trials before. This 2 nd person possessive reference indexes that the line to be reached is a line which is specifically relevant to the student's actions and which she should know to be so because of her prior experience - it is the line she has learnt to identify and use as a cue for organizing her actions. By these elliptical, indexical and presupposition-loaded design features, the instructor produces this instruction as a reminder which refers back to prior shared experience and which expects the student to be able to use the common ground achieved earlier for its understanding and for organizing her own actions. The instruction closes with an evaluative transition marker (genau, 'exactly', 04), indexing that the sub-task of reversing the car correctly into the parking space has been successfully completed instead of an explicit, descriptive noticing of the fact as in the second instruction (Extract 3), which was the first time the student rehearsed the procedure. The object of the assessment genau is the accomplishment of an imaginary line between the b-column of the driving school car's and the rear lights of the car in front in parallel to the sidewalk. This can only be understood by the student if she is able to identify the instructor's tacit expectations concerning the correct task-performance, which can be taken to be part of the common ground achieved in the two previous trials.

The last run we will consider is the final trial, which is the twelfth in total (closing a second series of trials two weeks later). After the student has successfully completed the task in three out of the four last trials, the instructor does not produce any verbal instruction anymore, but only observes the movement of the car gazing straight ahead (Figure 2). When the relevant line (between the b-column and the rear light of the car in front) is reached, the instructor turns her gaze to the right (i.e. the sidewalk, Figure 3). Immediately after the instructor's head movement, the 


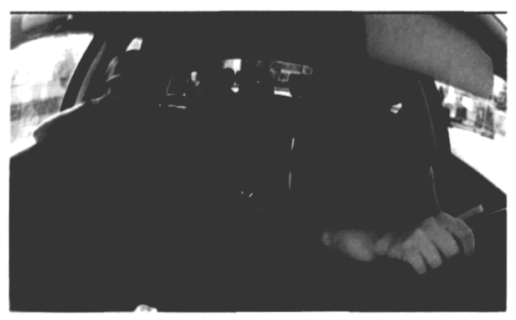

Figure 2. Instructor monitors trajectory of the car looking ahead (FAHR_02_20_57:47_12th-instruction)

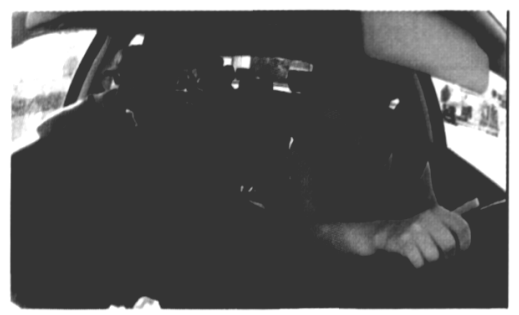

Figure 3. Instructor looks out of the right window as line between b-column and rear light of car parked in front is reached (FAHR_02_20_57:49_12th-instruction)

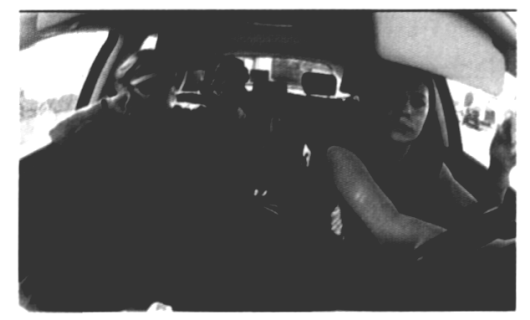

Figure 4. Instructor looks at student, who is turning steering wheel into the opposite direction (FAHR_02_20_57:50_12th-instruction)

student starts to turn the steering wheel into the opposite direction (Figure 4), as is required when the line is reached.

We have now reached a borderline case: It is neither clear if the instructor's monitoring head is produced as an instructing head point for the student nor if it is perceived as such by the student. It may as well be that both the instructor and the student simultaneously attend to the fact that the action-implicative landmark is reached. In this case, no instruction would be in play anymore, but only monitoring of the student's performance on the instructor's part. 
Table 1 summarizes the changes in the instructional formats over the four trials discussed above. While in the first two trials, the action to be performed is described, it is not mentioned anymore in later trials. The first two instructions are also produced with a complex, adverbial argument structure. ${ }^{3}$ In trial four there is only one main clause, in the last trial only a gestural hint is produced (if it is produced or understood as an instruction at all). While in the first trial multiple pointing gestures are used to refer to the line to be observed and the landmarks between which the line holds, in later trials there are only gestural references to the line. Overall, the complexity of the instructional formats decreases over trials in several dimensions of turn-construction and multimodal conduct.

Table 1. Changes of instructional formats in case 1 over trials

\begin{tabular}{|c|c|c|c|c|c|}
\hline $\begin{array}{l}\text { Number } \\
\text { of trial }\end{array}$ & $\begin{array}{l}\text { Description } \\
\text { of action }\end{array}$ & Syntax & $\begin{array}{l}\text { Number of } \\
\text { arguments }\end{array}$ & $\begin{array}{l}\text { Types of } \\
\text { argument }\end{array}$ & Gestures \\
\hline 1 & + & decl clause+adverbial & $3+3$ & $\begin{array}{l}1 \text { adverbial } \\
3 \text { lexical } \\
2 \text { PRO }\end{array}$ & $\begin{array}{l}3 \text { point } \\
2 \text { iconic }\end{array}$ \\
\hline 2 & + & IMP clause+adverbial & $2(3)+3$ & $\begin{array}{l}1(2) \text { adverbial } \\
2 \text { lexical } \\
2 \text { PRO ( } 1 \\
\text { deictic) }\end{array}$ & $\begin{array}{l}1 \text { point } \\
5 \text { iconic }\end{array}$ \\
\hline & - & $2 \mathrm{decl}$ & $2+2$ & $\begin{array}{l}2 \text { lexical } \\
2 \text { PRO }\end{array}$ & \\
\hline 4 & - & decl clause & 1 & 1 lexical & 1 iconic \\
\hline 12 & - & - & - & - & (1 gaze) \\
\hline
\end{tabular}

\subsection{Case 2}

The same pattern of change towards less complexity and increasing economy of instructional formats over time can be seen in the other cases. In case 2, the first run already starts with an implementation of reverse parking. However, the student is not expected to follow the instruction immediately, but only after the instructor has completed the instructional step by an understanding-check.

3. 'Argument structure' here does not refer only to the subject and direct objects. It includes all participants and circumstances (cf. Halliday and Mattiessen 2014, 310-355), i.e. also oblique cases and adjuncts. This conforms to the common understanding of 'arguments' in Construction Grammar (see e.g. Goldberg 2006). We also counted arguments embedded in complement clauses and not only the whole complement clause as one argument. 
Extract 5. FAHR_02_09_02:04-02:13_1st-instruction

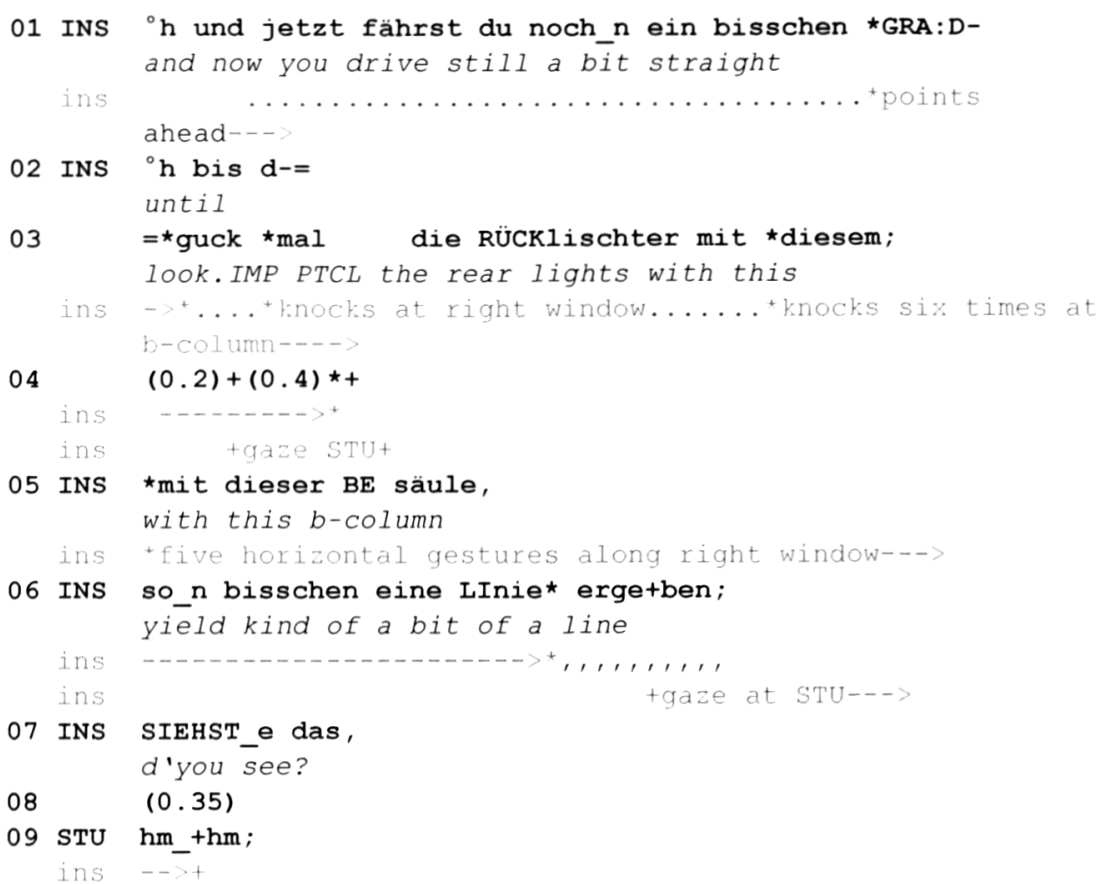

As in case 1 (Extract 1), the first instruction comprises a description of the action to be performed (jetzt fährst du noch ein bisschen [...], 'now you still drive bit [...]', $01 \mathrm{ff}$.). The turn consists of a complex declarative sentence with an adverbial clause specifying the point to which the car should be reversed. The latter involves the explicit categorization of three landmarks, the rear lights of the car in front, the b-column of the driving school car and the resulting line between them (03-06). The main clause exhibits three arguments (agent $=d u$, 'you', 01 ; manner $=g r a d$, 'straight', 01 ; location $=$ adverbial clause bis [...], 'until', 02-06), the adverbial clause itself does so as well (theme $=$ die rücklischter, 'the rear lights', 03; counter-theme $=$ mit dieser be säule, 'with this b column', 05; result = eine linie, 'a line', 06). All landmarks are lexically encoded. As in the first instruction in case 1, they are referred to by pointing gestures, first towards the car in front (01-03), then by knocking at the right window, the instructor points to the b-column (03-04). Equally, the line is indexed by horizontal iconic gestures (05-06). The instruction is also delivered in installments and closed by eliciting an understanding display from the student (07-09).

Like in case 1 (Extract 3), the student is already reversing the car into the parking space in the second run, while the instructor produces her instruction. She does not describe the action to be performed anymore. She does neither mention the coordinates between which the line to be observed holds. 
Extract 6. FAHR_02_09_05:06-05:13_2nd-instruction

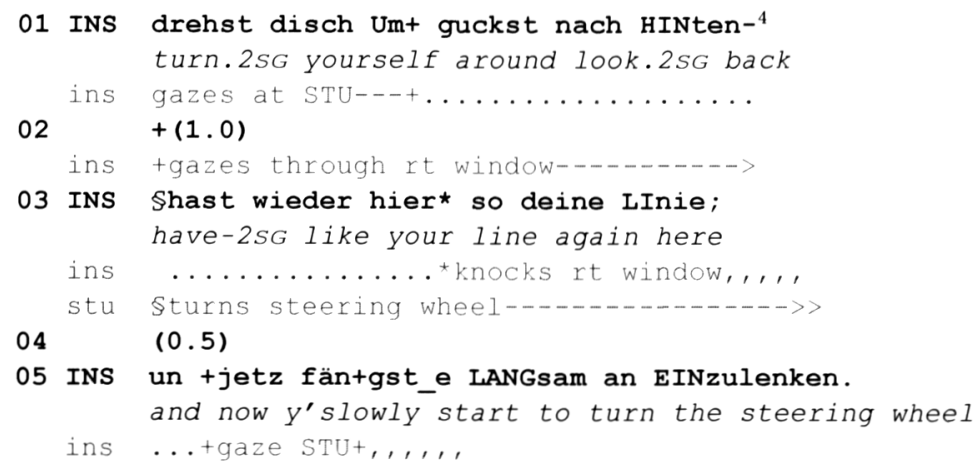

As in case 1, instruction 4 (Extract 4), the instructor here produces a declarative sentence (03), which only includes the possessive reference to the line the student is supposed to know and identify as the relevant landmark for turning the steering wheel into the opposite direction. This is actually what the student already starts to do in sync with the onset of the instructor's turn - and well ahead of the instructor's explicit request to do so in line 04 . Already in this second run, the instructor constrains the instruction to referring to the action implicative landmark, which, by the adverbial modifier wieder ('again'), is contextualized as being present another time, thus indexing its status as a non-first, reminding instruction. Again knocking at the window is used as pointing reference, this time to the line. The instructor monitors the student's actions and the movement of the car (by looking out of the window, observing the position of the car to the sidewalk) alternatingly, but she produces no understanding check. ${ }^{5}$

The instruction in the third run is even more indexical.

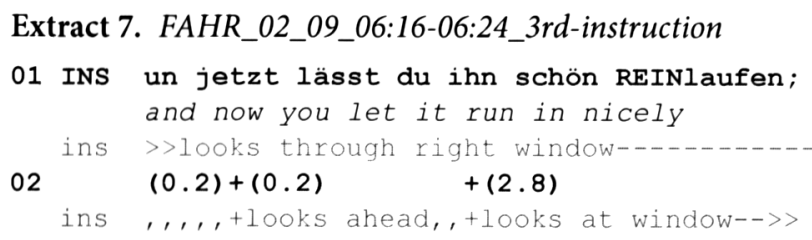

4. The requirement to look back when reversing the car applies to the whole process of reverse parking. A request for looking back is produced whenever the student fails to do this. These requests are not included in our analysis, because they do not specifically concern the skills which are peculiar to the sub-task in focus here.

5. The reduction and increasing indexicalization of the design of instructions can be seen to proceed in a faster pace in case 2 than in case 1 . This reflects that the instructor considers the student to be a more advanced and thus faster learner than the student from case 1 . 
The instructor here produces an action description by a directional deictic gloss, which is not supported by gesturing: jetzt lässt du ihn schön reinlaufen ('now you let it run in nicely', 01). This is a request to reverse the car back into the parking space. The precise spatial meaning is not expressed, but has to be inferred by the student. The causative formulation ascribes only little agency to the student, meaning that he should not turn the steering wheel further while reversing. Both arguments are pronominal (agent $=d u$, 'you'; patient $=i h n$, 'him', meaning the car). No landmarks are mentioned and no gestures used, either. This time, the student only starts to turn the steering wheel into the opposite direction when the instructor asks him to do so (03). This can be seen as an effect of learning, because in the prior trial (see Extract 6, line 03), the student turned too early, which led to the car being positioned too far away from the sidewalk as its unwanted result. The instructor does not elicit understanding displays and monitors only the movement of the car, but not the student.

In the next, fourth run, the instructor does not produce any instruction. She restricts herself to partial monitoring of the movement of the car and engages in multi-activity. She thus displays that she is no longer fully engaged with the pedagogical activity of rehearsing the task.

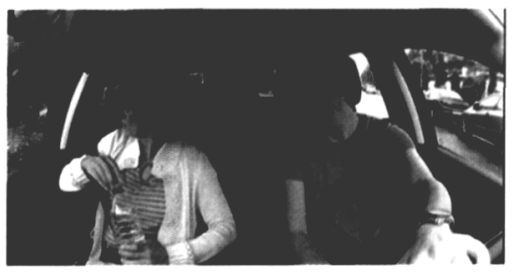

Figure 5. Multi-activity: Instructor opens bottle and looks to tree where a bird is singing

After the student has failed to position the car correctly in the fourth and fifth runs, the instructor produces a short elliptical reminder in the sixth run.

Extract 8. FAHR_02_09_13:53-13:55_6th-instruction

01

02

$\star(0.4)$

03 INS LIn*ie,

line

03

$(0.2)$

The instructor closely monitors the movement of the car towards the sidewalk. By a horizontal, iconic gesture she enacts the achievement and the relevance of the line 
already before it is verbally expressed ( $02 \mathrm{f})$, this time by a bare noun. Using a bare noun as an action-implicative reference is another way to formulate a reminder: It presupposes and reflexively indexes the shared interactional history of having learnt to know the relevant coordinates, to identify the line and to understand its practical relevance - and, of course, the student's comprehension that the instructor's turn is to be taken as an instruction. The de-agentive and impersonal formulation can be taken to index the routine character of the instructed action. The instructor again monitors only the movement of the car, but not the student.

Table 2 summarizes changes in instructional formats over interactional history in case 2 . We basically find the same kinds of changes over time as in case 1 : Instructional formats become increasingly shorter, actions and landmarks which were first explicitly introduced become presupposed later, explicit instructions are replaced by indexical reminders. While initially various coordinates are referred to by pointing, gestures are later restricted to the essential action-implicative landmark. In contrast to case 1, already the second instruction (and not only later instructions) exhibits all properties of reflexively indexing its being a non-first and that common ground is presupposed for its correct understanding. Later instructions are formatted as reminders, which, as a response to student's failures, either in current performance or in prior trials, may be amended again by aspects which had been absent in instructions in prior runs.

Table 2. Changes of instructional formats in case 2 over trials

\begin{tabular}{|c|c|c|c|c|c|}
\hline $\begin{array}{l}\text { Number } \\
\text { of trial }\end{array}$ & $\begin{array}{l}\text { Description } \\
\text { of action }\end{array}$ & Syntax & $\begin{array}{l}\text { Number of } \\
\text { arguments }\end{array}$ & $\begin{array}{l}\text { Types of } \\
\text { argument }\end{array}$ & Gestures \\
\hline \multirow[t]{3}{*}{1} & + & 2 main clauses & $1+2$ & 4 lexical & 3 point \\
\hline & & $1 \mathrm{ADV}$ & $1+4$ & 3 PRO & 2 iconic \\
\hline & & $1 \mathrm{COMP}$ & & 1 adverbial & \\
\hline \multirow[t]{3}{*}{2} & - & main clause & 3 & 1 lexical & 1 point \\
\hline & & & & 1 PRO & \\
\hline & & & & 1 deictic & \\
\hline 3 & - & main clause & 2 & 2 PRO & - \\
\hline 4 & - & - & - & - & \\
\hline 6 & - & bare noun & - & 1 lexical & 1 iconic \\
\hline
\end{tabular}




\subsection{Case 3}

In case 3, an even more experienced student, who already owns a motorcycle license, is being taught. His process of learning is faster, and so is the cline of reduction of instructional activities. Again the first instruction involves toy cars, while the car is standing, and should not be followed in situ.

Extract 9. FAHR_02_03_53:21-53:32_1st-instruction

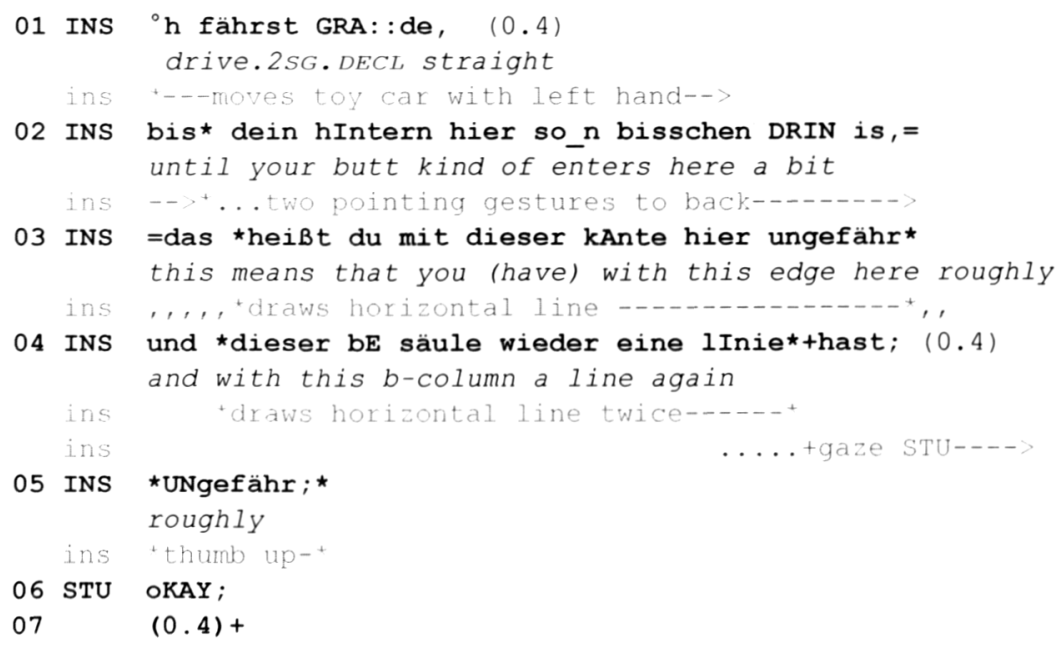

The instructional turn is a complex declarative description with a main clause and two adverbial clauses. The main clause includes two arguments $($ manner $=$ grade, 'straight', 01; location = adverbial clause, 02), the adverbial clause in 02 has three arguments (theme $=$ dein hintern, 'your butt'; location $=$ hier, 'here'; degree $=$ so $\_n$ bisschen, 'a bit'), the reformulation of the adverbial in 03-05 involves five arguments (agent $=d u$, 'you'; theme $=$ mit dieser kante, 'with this edge' (meaning the left rear corner of the car in front); counter-theme = mit dieser be säule, 'with this b-column'; result = eine linie, 'line'; degree = ungefähr, 'roughly'). The description includes the action to be performed and the explicit lexical categorization of four landmarks ('your butt', 'edge', 'b-column', 'line'), two of which are referred to also by pointing (the butt in 02) and horizontal, iconic enacting gestures (the line in $03 \mathrm{f})$. In addition, the gesture of placing the toy car enacts the action of reversing the car (01). An understanding-display of the student closes the instruction (06). In contrast to cases 1 (Extract 1) and 2 (Extract 5), the instructor does not produce this first instruction in clearly segmented installments, but for the main part in a rush-through manner (02-04; cf. Schegloff 1987) and she does not use a verbal token to elicit an understanding display from the student (however, she gazes at him 
as the instruction is closed, 04-07). This first instruction is formulated in a much more casual way as in cases 1 and 2. This may index that this student is positioned as an experienced student who is not in need of a maximally precise instruction.

In the second run, the first implementation of the task follows. The student is already reversing the car.

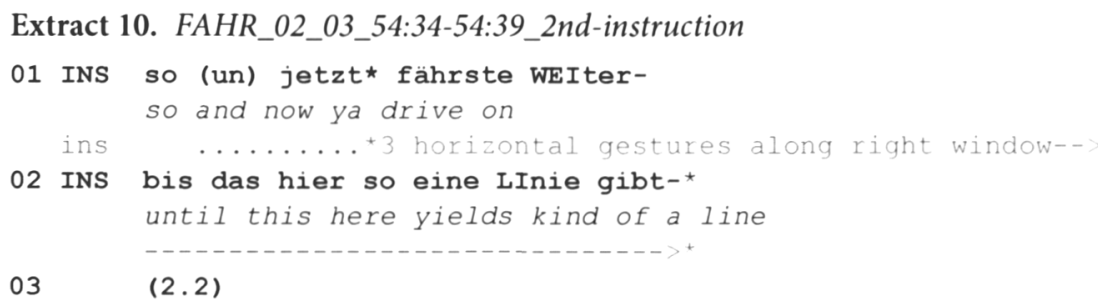

As in the first run (Extract 9), the instruction is produced in a declarative format, although with a much leaner syntax. It consists of a main clause, now with a cliticized subject and one location argument, ${ }^{6}$ the following adverbial clause, which itself exhibits two arguments (location = hier, 'here'; result = linie, 'line'). The description is much more indexical than the first. It does not explicitly mention the landmarks between which the line holds. Instead, it refers to them with the vague local deictic hier, accompanied by horizontal iconic gestures which enact the line. The instructor monitors the movement of the car, but not the student's actions and does not check his understanding, either.

In the next two runs, the instructor does not produce an instruction anymore. This is probably due to the fact that all trials of the student so far have been successful. In the third run, the instructor still monitors closely the student's actions (Figure 6), the car movement (Figure 7) and the progression of the car to the line between the b-column and the rear light of the car in front (Figure 8).

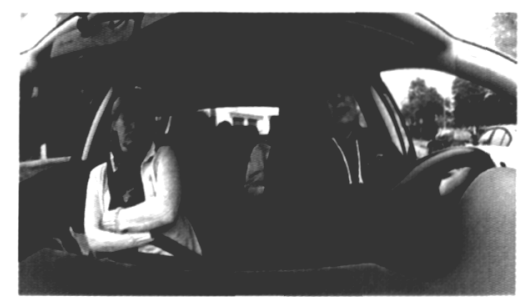

Figure 6. Instructor monitors student manipulating the steering wheel (3rd run)

6. The assignment of arguments depends here on whether the cliticized subject is counted as agent and whether weiter is regarded as an isolated verb particle or as adverbial with a directional role (cf. footnote 2). 


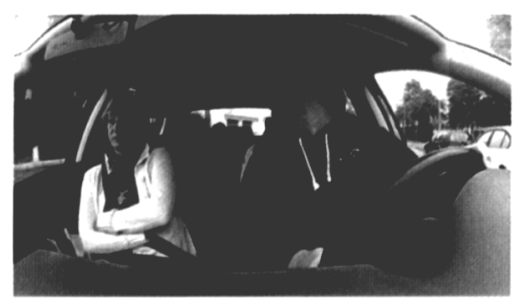

Figure 7. Instructor monitors trajectory of the car (3rd run)

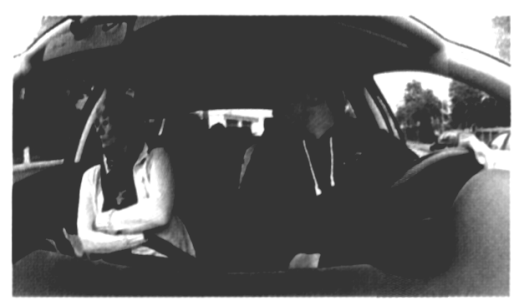

Figure 8. Instructor monitors distance to the sidewalk (3rd run)

In the fourth run, however, the instructor only partially monitors the student's actions and the car movement. Instead, she smiles at the student as a sequel to a sequence of topical talk before (Figure 9). Thus, as in case 2, Figure 5, she displays reduced engagement in the pedagogical joint activity of rehearsing the task by temporally engaging in another line of action.

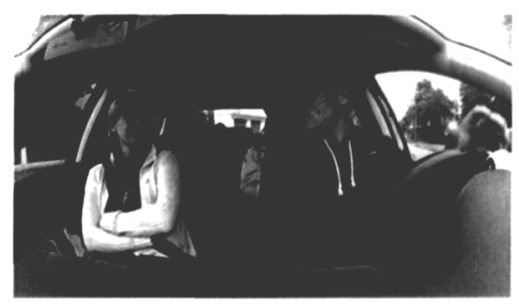

Figure 9. Instructor smiles at student (4th run)

Table 3 summarizes the process of the increasing reduction and indexicalization of the instructional turns in case 3 . The same kinds of changes in action-formation as in cases 1 and 2 can be found, but the process until instruction is no more necessary is much faster in case 3 . This is probably due to the fact that the student is already an experienced driver, who has shown that he learns fast in other task-performances. 
Table 3. Changes of instructional formats in case 3 over trials

\begin{tabular}{lcllll}
\hline $\begin{array}{l}\text { Number } \\
\text { of trial }\end{array}$ & $\begin{array}{l}\text { Description } \\
\text { of action }\end{array}$ & Syntax & $\begin{array}{l}\text { Number of } \\
\text { arguments }\end{array}$ & $\begin{array}{l}\text { Types of } \\
\text { argument }\end{array}$ & Gestures \\
\hline 1 & + & 1 main clause + 2 ADV & $2+3+5$ & $\begin{array}{l}7 \text { lexical } \\
1 \text { adverbial } \\
1 \text { PRO }\end{array}$ & $\begin{array}{l}3 \text { point } \\
2 \text { iconic }\end{array}$ \\
& & & & $\begin{array}{l}1 \text { deictic } \\
1 \text { lexical }\end{array}$ & 3 iconic \\
& & & & 1 adverbial & \\
2 & + & 1 main clause + 1 ADV & $1+2$ & 1 deictic & \\
& & & & - & - \\
3 & - & - & - & - & - \\
\hline
\end{tabular}

\section{Quantitative findings}

In Section 5 we have analyzed in detail the changes in turn-construction and multimodal conduct over time in instructions of a sub-task of reverse parking in three cases. In this section, we will adopt a broader view, summarizing the quantitative findings from exhaustive coding of 39 runs of trials of reverse parking with the same instructor involving four students in total. Each run included four sub-tasks:

- Orient the car straight on the road in parallel to a parked car keeping a distance of approximately one meter.

- Reverse the car until its b-column reaches the end of the parked car.

- Reverse car into the parking space - this sub-task was considered in Section 5.

- Position car straight in parallel to the sidewalk in a distance of not more than approximately 30 centimeters.

Additionally, sometimes a post-trial discussion followed a run (mostly after failed trials).

Our initial hypothesis was that changes of recipient design are related to interactional history overall, i.e. to the number of trials. However, the findings of our qualitative study, part of which we have reported on in Section 5, suggested more specific expectations:

- First instructions are more elaborate than all following instructions.

- If the student does not carry out a sub-task correctly or if the student had failed the sub-task in the prior trial, instructions are more elaborate than if the student had performed the prior trial successfully and is performing the ongoing sub-task correctly. 
In other words, we expected that there is a difference between learning (successful performance) and the accumulation of common ground over interactional histories without (sufficient) learning. We therefore distinguish four different variants of the variable 'interactional history and learning': first instruction (by toy cars), first implementation, instruction after/upon failure, instruction after success. In the figures below, scores for 'instruction after/upon failure' and 'instruction after success' are aggregated for all instances in which the student had failed or had been successful.

In order to identify quantitative patterns of change related to the variable 'interactional history and learning', the following dependent variables of the instructional turns were coded: The numbers of
a. instructions per sub-task,
b. words used per sub-task,
c. turns per sub-task,
d. understanding-checks per sub-task, and the
e. complexity of argument structure per instruction. ${ }^{?}$

Since our analysis rests on only four students, among whom the number of trials is not equal, and since all measures are dependent measures, we decided to perform statistical tests only if the amount of data was sufficient. We present the reader with descriptive statistics in order to be able to assess the possible relevance of numerical differences for a better understanding of how interactional histories effect changes in recipient design. We now discuss the findings for the dependent variables of turn-design. Findings for (a)-(e) have proved to be statistically significant $\left(p<0.01^{\star *}\right)$.

\section{a. Instructions per sub-task (Figure 10)}

The number of instructions decreases only after the first implementation of the driving rehearsal, but not already after the first instruction. ${ }^{8}$ The instructional steps which are included in the toy car demonstration are explicitly repeated in the first implementation. Sometimes additional instructions are produced, mainly having

7. As one 'instance of an instruction', we count every instructional TCU or turn which makes at least one specific instructed action relevant from the student. Thus, questions, understandingchecks, assessments and comments by the instructor do not count as instructions, but they may be part of instructions. Post-trial instructions which discuss problems with prior performances and instructions are not included in the analysis, except for the analysis of the number of turns, for which they have been counted separately (see below).

8. Note that case 3 discussed in Section 5.3 is an exception in this respect, because in case 3 the second instruction of the sub-task of reversing into the parking space was considerably shorter than the first. 
to do with looking backward and adapting speed and handling of the clutch. These requirements are not mentioned in the toy car demonstration, because they do not concern skills which are specific for the task and thus do not have to be learnt for the first time.

For the trials after the first implementation, we found that if the student was successful in the prior trial and performs correctly in the ongoing trial, mostly no more (verbal) instruction is produced. If the prior trial failed or of the current task-performance is faulty, instructions specifically focus the problematic steps of action.

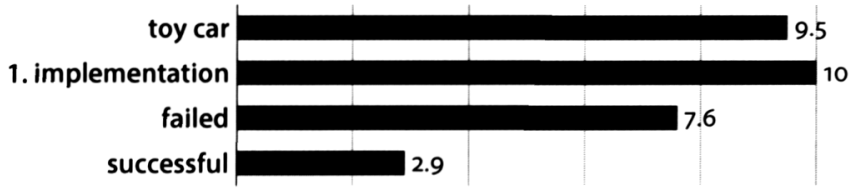

Figure 10. Number of instructions per sub-task $(N=245,39$ trials, 4 students $)$

\section{b. Words per sub-task (Figure 11)}

Instructions do not only become less, but the individual instructions also become shorter (cf. also Broth et al. 2017). Already in the first implementation we find a slight decrease in the number of words used per sub-task. Instructions in response to failure are much longer than instructions with a successful learner (if they occur at all, see above). But still, instructions after failure are much less explicit than first instructions and instructions in first implementations. We could show in the qualitative analysis in Section 5 that this difference is due to the design of later instructions as highly indexical and sometimes elliptical reminders which presuppose much instructional detail which was explicitly conveyed in the first, but often also still in the second run. Instructions after success are most elliptical, if there is an instruction at all.

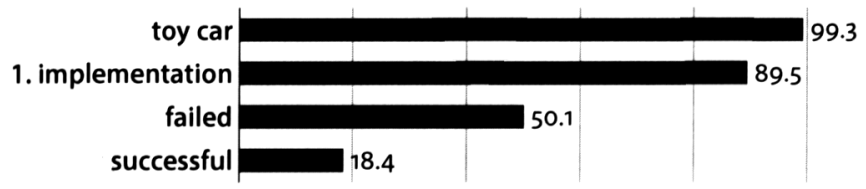

Figure 11. Number of words per sub-task $(N=1742,39$ trials, 4 students $)$

9. Cliticized items were not counted separately; response tokens, sound objects and other interjections were counted as words. 


\section{c. Turns per task (Figure 12)}

'Turns per sub-task' include all turns by both participants per sub-task, i.e. not only instructions, but also questions, comments, assessments and merely responsive acknowledgements and understanding displays (by the student). The figures show that interactional sequences during sub-task-performances involve less speaker changes over time. Especially in the very first (toy car) instruction, the student is led to produce verbal displays of understanding (as we could see in the cases analysed in Section 5, see also d) below). If the student has been successful, the task is mostly rehearsed in silence.

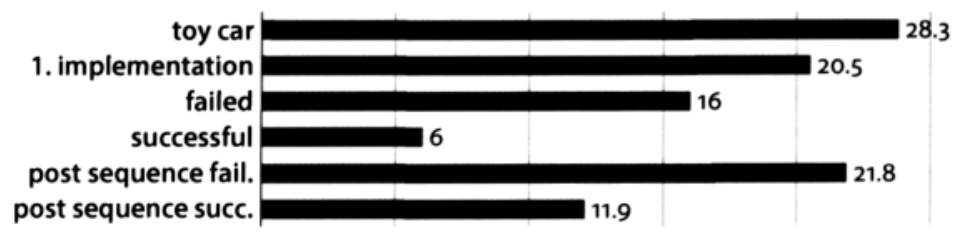

Figure 12. Number of turns per task $(N=720,39$ trials, 4 students $)$

d. Understanding-checks per sub-task (Figure 13) ${ }^{10}$

Understanding-checks are almost only produced in first instructions. They regularly close the instruction of a sub-task and they are used to highlight the most relevant landmarks, actions and notions to be learnt.

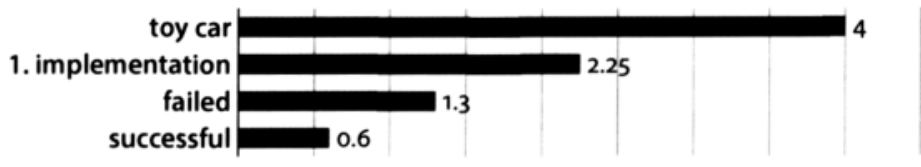

Figure 13. Number of understanding checks per sub-task ( $N=61,39$ trials, 4 students)

\section{e. Complexity of argument structure (Figure 14)}

More complex syntax is used if the car is not moving, i.e. in toy car instructions and post-trial discussions. This reflects that landmarks have to be made explicit, because they are not (unambiguously) visually available if the car and the passengers are not

10. Only verbal understanding-checks are counted, but not instances of turning the gaze towards the student, which may equally be treated as requests for displays of understanding (see the first run of case 3 in 5.3). 
positioned the way they would be in the instructed sub-task. More specifically, first instructions using toy cars are produced with the most complex argument structure per verb ( $>2$ arguments) and mostly with adverbial clause constructions. Argument structure complexity decreases uniformly, except for a more radical loss in case of successful learning, where often elliptical and de-transitive structures are used. In addition, as we could see in Extract (8), there may not only be a decrease in number of arguments in later trials, but the verb may also be omitted.

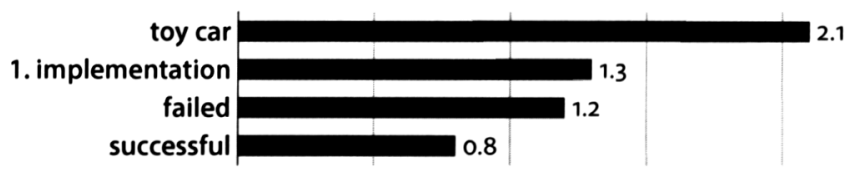

Figure 14. Number of arguments per verb

In addition to these variables, which lend themselves to quantitative comparison over time, changes in other properties of turn-design seem to be related to interactional histories as well:

a. Syntax: First instructions were always produced by complex declarative sentences. Only in later instructions, other syntactic formats such as imperatives, deontic infinitives, free nominal phrases, bare nouns and various other verb-less ellipses are used (see Deppermann 2018). If notions and actions are introduced for the first time, declaratives are always used. Declaratives mostly have a richer argument structure than the other syntactic formats. In contrast, the other formats are used as 'reminders' which mandate an action which is taken to be known to be due, which is simple and to be performed without problems and which is or at least should be part of the routine repertoire of the student (see Deppermann 2018).

b. Increasing indexicality of reference: The case analyses in Section 5 have shown how references by lexical NPs are replaced by pronominal or other kinds of deictic references in later runs. Possessive constructions (like 'your line' in 5.1, Extract (4) and 5.2, Extract (6)) index the specific association of objects to the learner and their duties which has been established in prior trials.

c. Increasing implicitness: Landmarks to be observed and actions to be performed become increasingly presupposed and are not mentioned anymore. References to landmarks, but also (transitional and evaluative) interjections become action-implicative, as they imply requests for student actions. Turns also become more elliptical in their syntax. Rarely, stand-alone gestures may be used to refer to action-implicative landmarks in late trials (as possibly in case 1 in Section 5.1, Figures 2-4). 
Furthermore there are two practices which are specific for first instructions:

d. Coining canonical terms: Instructors introduce and define canonical terms. They refer to objects, landmarks, states and events (like b-column (see Extract (2) in footnote 1), $45^{\circ}$ degree angle, biting point) and to actions (like orient the car, look far ahead) which are crucial components of the skills to be learnt (see Deppermann 2016). These terms amount to instructional "conceptual pacts" (Brennan and Clark 1996) - they will be reused later as canonical names for reference.

e. Prosodic mise en relief: In first instructions, key terms and newly introduced canonical terms are sometimes highlighted by extraordinary pitch peaks, lengthening and enhanced articulatory precision (see Deppermann 2016). However, prosodic highlighting is also sometimes used if students repeatedly fail to comply with a request.

\section{Discussion}

This chapter contributes to the study of the emergence of recipient design in interpersonal relationships over time. It provides evidence that changes in recipient design build on shared interactional histories of the participants and it shows which aspects of turn-construction are subject to change over time. Over interactional histories, participants increasingly rely on highly indexical and elliptical practices indexing the to-be-known-in-common routine character of joint action. The accumulation of common ground thus not only affects referential practice (cf. Clark and Marshall 1981; Clark and Wilkes-Gibbs 1986; Isaacs and Clark 1987; Schegloff 1972; Sacks and Schegloff 1979), but also action-formation: imperatives, deontic infinitives, action-implicative descriptions/references and discourse particles are resources to perform instructions which build on shared interactional histories and can do without the higher degree of explicitness and verbal precision which is usually realized in descriptions used in first instructions.

The notion of 'interactional history' is a wide and vague one, possibly including all sorts of experiences people make in the presence of one another. The notion does not define whether it relates only to actions in interaction or also to other perceptions and experiences talked about, whether it is confined to interpretations of in-situ-experiences which are intersubjectively shared and it does not address if and how sharing is mutually displayed. In this study, interactional histories are studied by focusing on consecutive series of the same kinds of task-related actions which two people perform together. The relevant interactional history which has been methodologically considered is thus limited to the shared history of joint 
task-performance. Of course, this is a methodological reduction, because instructor and student share much more common experiences than just participating in this type of joint activity. Some of the differences in the three cases considered in Section 5 have already suggested that other shared experiences and categorical assessments of the more general driving skills of the learner also enter into the instructor's turn-design. Still, the high degree of consistency of the overall patterns of change in the cases analyzed shows the enormous degree to which the specific history of prior shared experience with the same type of joint action is used by participants to build on as a common ground for future joint action.

In contrast to the emerging line of studies on the development of interactional competences (Pekarek Doehler and Fasel Lauzon 2015; Pekarek Doehler and Pochon-Berger 2015; Berger and Pekarek Doehler 2018), the changes over time in action-formation are related to the learning process of the recipient and not of the speaker. Changes in recipient design reflect the trajectory of other-positioning of the student by the instructor from a novice to a competent driver. In the first instruction, the student is treated as a novice who is in need of explicit and comprehensive instruction and whose understanding process is closely monitored and checked. Over the course of repeated successful trials, the increasingly lean design of the instructions and the decreasing intensity of the monitoring of the student's performance reflects the growing trust that the student has acquired relevant skills. The student thus is increasingly positioned as a competent driver who is not in need of instruction anymore and who is finally able to perform the task self-initiatedly in the correct manner given the relevant contextual cues. Still, changes in recipient design of instructions do not simply reflect learning. Even if the student has failed prior task-performances or if their performance of the ongoing task is faulty, $\mathrm{s} / \mathrm{he}$ is not treated like a novice anymore in instructions in later trials. Instead, $s /$ he is positioned by the design of the instructor's turns as a not-yet-competent driver, who has access to at least part of the relevant knowledge at least in principle. This is reflected by the design of instructions as indexical-elliptical reminders, which index that an instruction is not a first instruction, but that it builds on the should-have-known or known-in-principle character of the instructed action. Still other practices, which have not been discussed in this chapter, such as knowledge checks, negative contrasts of correct and faulty performance and moralizing about failures, are additionally used and act as to position the student as a not-yet-competent driver who, however, should be able to draw on common ground for correct task-performance. In sum, the patterns of changes over time and their relationship to shared interactional histories and the development of students' task-performances show that both students' acquisition of skills (learning) and the accumulation of common ground between instructor and student (shared experience) account for changes 
in recipient design. Both sources are only partially related. While learning builds on accumulating common ground, instructors clearly distinguish between novices and partners with how they share common ground on the one hand and between common ground and learning on the other hand.

The study gives evidence of the sensitivity of interactional conduct to interactional histories beyond the current sequential context. It shows how people build the design of their actions on the embeddedness of action within a larger temporal framework of shared past experiences and their recurrence. Practices of recipient design are continuously in flux and updated due to shared interactional experience. While participants necessarily presume intersubjectivity in order to act, they use experiences of intersubjective grounding in the past and the ongoing evidence of co-participants' understanding and action-orientation for the continuous, situated adaption of recipient design. The situated deployment of embodied multimodal resources thus is sensitive to the temporalities of interactional histories of shared experience and it relies on cognitive processes (memory and common ground), which are reflexively indexed and cued by the design of actions. There is a trade-off between the deployment of multimodal resources, above all: the complexity of linguistic design, and the requirements on the complexity of cognitive processes in terms of situated inferences (cf. Bisang 2014, 2015) and the complexity of interactional sequences. If little common ground is available, the linguistic complexity of turn-design is comparatively high and interactional sequences are more extended by explicit grounding procedures. When joint action becomes routine and common ground to rely on has been accumulated, however, participants increasingly use highly indexical formats of turn-design and build condensed action sequences. More specifically, the decreasing complexity of turn-construction (leaner argument structure, ellipsis, substitution of lexical references by more indexical means (deictics, pronouns, discourse particles, omission of action descriptions and spatial references, etc.) rests on the expectation that the recipient is able to fill in the gaps, i.e. accommodate presuppositions, identify relevant spatial reference points and requirements on action by themselves, infer referential meanings and reference/ description-implied actions. In sum, over interactional histories joint embodied, indexical routines and cue-driven inferences increasingly take the place of explicit linguistic resources and reciprocal sequential negotiation. 


\section{Acknowledgement}

Talks related to this article have been presented at the 4 th annual meeting of the network 'Mobilities in Interaction' (MOBSIN4) in Aalborg/DK, May 24, 2014, at the Center of Excellence for Intersubjectivity in Interaction (Helsinki/FIN), March 4, 2015, at the workshop on 'Kognition und Konversation' (Düsseldorf/D), December 8, 2015, and as a keynote lecture at the 'Complexity Meeting' of the Laboratoire d'Excellence ASLAN (Études Avancées sur la Complexité du Langage, Lyon/F), June 16, 2016. I thank the participants of these events for valuable comments. Jürgen Streeck, Jörg Zinken and my colleagues in the project on 'interactional constitution of meaning' at the IDS Mannheim have provided helpful feedback on the first draft of this text. Darja Enns participated in recording and coding data.

\section{References}

Berger, Evelyne, and Pekarek Doehler, Simona. 2018. Tracking Change Over Time in Storytelling Practices: A Longitudinal Study of Second Language Talk-in-Interaction. In Longitudinal Studies on the Organization of Social Interaction, ed. by Pekarek Doehler, Simona, Wagner, Johannes, and Esther González-Martínez, 67-102 . Basingstoke: Palgrave.

Bisang, Walter. 2014. "Overt and Hidden Complexity - Two Types of Complexity and Their Implications". Poznan Studies in Contemporary Linguistics 50 (2): 127-143. doi: 10.1515/psicl-2014-0009

Bisang, Walter. 2015. "Hidden Complexity - The Neglected Side of Complexity and Its Implications." Linguistics Vanguard 1 (1): 177-187. doi:10.1515/ingvan-2014-1014

Brennan, Susan E., and Herbert H. Clark. 1996. "Conceptual Pacts and Lexical Choice in Conversation." Journal of Experimental Psychology: Learning, Memory, and Cognition 22: 1482-1493.

Broth, Mathias, Levin, Lena, and Jakob Cromdal. 2017. "Starting Out as Driver. Progression in Instructed Pedal Work." In Memory Practices and Learning - Interactional, Institutional and Sociocultural Perspectives, ed. by Mäkitalo, Åsa, Linell, Per, and Roger Säljö, 113-142. Charlotte NC: Information Age.

Clark, Herbert H. 1996a. "Communities, Commonalities, and Communication." In Rethinking Linguistic Relativity, ed. by Gumperz, John J., and Stephen C. Levinson, 324-355. Cambridge: CUP.

Clark, Herbert H. 1996b. Using Language. Cambridge: CUP. doi: 10.1017/CBO9780511620539

Clark, Herbert H., and Catherine R. Marshall. 1981. "Definite Reference and Mutual Knowledge." In Elements of Discourse Understanding, ed. by Joshi, Aravind K., Webber, Bonnie L., and Ivan A. Sag, 10-63. Cambridge: CUP.

Clark, Herbert H., and Deanna Wilkes-Gibbs. 1986. "Referring as a Collaborative Process." Cognition 22: 1-39. doi:10.1016/0010-0277(86)90010-7

Clark, Herbert H., and Susan A. Brennan. 1991. "Grounding in Communication." In Perspectives on Socially Shared Cognition, ed. by Resnick, Lauren B., Levine, John M., and Stephanie D. Teasley, 127-149. Washington: APA Books. doi:10.1037/10096-006 
Deppermann, Arnulf, and Axel Schmidt. 2016. "Partnerorientierung zwischen Realität und Imagination: Anmerkungen zu einem zentralen Konzept der Dialogtheorie." Zeitschrift für Germanistische Linguistik 44 (3): 369-405. doi:org/10.1515/zgl-2016-0021

Deppermann, Arnulf, and Reinhold Schmitt. 2009. “"damit sie mich verstehen”: Genese, Verfahren und recipient design einer narrativen Performance." In Theatralität des sprachlichen Handelns, ed. by Buss, Mareike, Habscheid, Stephan, Jautz, Sabine, Liedtke, Frank, and Jan-Georg Schneider, 79-112. München: Fink.

Deppermann, Arnulf. 2014. “"Don't Get Me Wrong”: Recipient Design by Using Negation to Constrain an Action's Interpretation." In Grammar and Dialogism, ed. by Bücker, Jörg, Günthner, Susanne, and Wolfgang Imo, 15-52. Amsterdam: John Benjamins.

Deppermann, Arnulf. 2015a. "When Recipient Design Fails: Egocentric Turn-Design of Instructions in Driving School Lessons Leading to Breakdowns of Intersubjectivity." Gesprächsforschung - Online-Zeitschrift zur verbalen Interaktion 16: 63-101. http://www. gespraechsforschung-online.de/fileadmin/dateien/heft2015/ga-deppermann.pdf, accessed: June 8, 2018.

Deppermann, Arnulf. 2015b. "Retrospection and Understanding." In Temporality in Interaction, ed. by Deppermann, Arnulf, and Susanne Günthner, 57-94. Amsterdam: Benjamins.

Deppermann, Arnulf. 2016. "La définition comme action multimodale pour des enjeux pratiques: Définir pour instruire à l'auto-école." Langages 204(4): 83-101.

Deppermann, Arnulf. 2018. "Instructional Practices in Driving Lessons in German: Differential Uses of Declaratives and Imperatives." International Journal of Applied Linguistics. doi: org/10.1111/ijal.12198

Fischer, Kerstin. 2016. Designing Speech for a Recipient. The Roles of Modeling, Alignment and Feedback in So-Called "Simplified Registers". Amsterdam: Benjamins.

Goodwin, Charles. 1979. "The Interactive Construction of a Sentence in Natural Conversation." In Everyday Language: Studies in Ethnomethodology, ed. by Psathas, George, 97-121. New York: Irvington.

Goodwin, Charles. 2017. Cooperative Action. Cambridge: CUP.

Halliday, Michael A. K., and Christian M. I. M. Matthiessen. 2014. Halliday's Introduction to Functional Grammar. 4th ed. New York: Routledge.

Husserl, Edmund. 1995[1929]. Cartesianische Meditationen. Hamburg: Meiner.

Hutchby, Ian. 1995. "Aspects of Recipient Design in Expert Advice-Giving on Call-in Radio." Discourse Processes 19 (2): 219-238. doi:10.1080/01638539509544915

Isaacs, Ellen A., and Herbert H. Clark. 1987. "References in Conversations between Experts and Novices." Journal of Experimental Psychology: General 116 (1): 26-37. doi: 10.1037/0096-3445.116.1.26

Linell, Per. 2009. Rethinking Language, Mind, and World Dialogically: Interactional and Contextual Theories of Human Sense-Making. Charlotte, NC: Information Age.

Maynard, Douglas W. 1989. "Perspective-Display Sequences in Conversation." Western Journal of Speech Communication 53: 91-113. doi:10.1080/10570318909374294

Mondada, Lorenza. 2015. “The Facilitator's Task of Formulating Citizens' Proposals in Political Meetings: Orchestrating Multiple Embodied Orientations to Recipients." Gesprächsforschung 16: 1-62, http://www.gespraechsforschung-online.de/fileadmin/dateien/heft2015/gadeppermann.pdf, accessed June 8, 2018. 
Mondada, Lorenza. 2018. "Multiple Temporalities of Language and Body in Interaction: Challenges for Transcribing Multimodality." Research on Language and Social Interaction 51 (1), 85-106.

Pekarek Doehler, Simona, and Evelyne Pochon-Berger. 2015. “The Development of L2 Interactional Competence: Evidence from Turn-Taking Organization, Sequence Organization, Repair Organization and Preference Organization." In Usage-Based Perspectives on Second Language Learning, ed. by Cadierno, Teresa, and Søren W. Eskildsen, 233-267. Berlin: De Gruyter Mouton. doi: 10.1515/9783110378528-012

Pekarek Doehler, Simona, and Virginie Fasel Lauzon. 2015. "Documenting Change across Time: Longitudinal and Cross-Sectional CA Studies of Classroom Interaction." In Handbook of Classroom Interaction, ed. by Markee, Numa, 409-424. Hoboken, New Jersey: WileyBlackwell.

Pekarek Doehler, Simona, Wagner, Johannes, and González-Martínez, Esther (Eds.) 2018. Longitudinal Studies on the Organization of Social Interaction. Basingstoke: Palgrave.

Pickering, Martin J., and Garrod, Simon. 2004. “Toward a Mechanistic Psychology of Dialogue." Behavioral and Brain Sciences 27: 169-225. doi:10.1017/S0140525X04000056

Sacks, Harvey, and Emanuel A. Schegloff. 1979. "Two Preferences in the Organization of Reference to Persons in Conversation and Their Interaction." In Everyday Language, ed. by Psathas, George, 15-21. New York: Center for the Study of Ethnomethodology and Conversation Analysis.

Sacks, Harvey, Schegloff, Emanuel A., and Gail Jefferson. 1974. "A Simplest Systematics for the Organization of Turn-Taking for Conversation." Language 50(4): 696-735. doi: $10.1353 /$ /an.1974.0010

Sacks, Harvey. 1992. Lectures on Conversation. 2 Vols. Oxford: Blackwell.

Schegloff, Emanuel A. 1972. "Notes on a Conversational Practice: Formulating Place." In Studies in Social Interaction, ed. by Sudnow, David N., 75-119. New York: The Free Press.

Schegloff, Emanuel A. 1987. "Recycled Turn Beginnings: A Precise Repair Mechanism in Conversation's Turn-Taking Organization.” In Talk and Social Organization, ed. by Button, Graham, and John Robert E. Lee, 70-85. Clevedon: Multilingual Matters.

Schegloff, Emmanuel A. 1996. "Some Practices for Referring to Persons in Talk-in-Interaction: A Partial Sketch of a Systematics." In Studies in Anaphora, ed. by Fox, Barbara A., 437-485. Amsterdam: Benjamins. doi: 10.1075/tsl.33.14sch

Schütz, Alfred. 1971[1945]. “On Multiple Realities." In his Collected papers I: The Problem of Social Reality, 207-259. Den Hague: Nijhoff.

Schütz, Alfred. 1974[1932]. Der sinnhafte Aufbau der sozialen Welt. Frankfurt am Main: Suhrkamp. Selting, Margret et al. 2009. “Gesprächsanalytisches Transkriptionssystem 2 (GAT 2).” Gesprächsforschung - Online-Zeitschrift zur verbalen Interaktion 10: 353-402. www.gespraechsforschungozs.de/heft2009/px-gat2.pdf, accessed June 8, 2018.

Sidnell, Jack. 2014. “The Architecture of Intersubjectivity Revisited." In Cambridge Handbook of Linguistic Anthropology, ed. by Enfield, Nick, Kockelman, Paul, and Jack Sidnell, 364-399. Cambridge: CUP. doi: $10.1017 /$ CBO9781139342872.018

Svennevig, Jan. 2015. "Én porsjon om gangen. Multimodal koordinering i samtaler med andrespråksbrukere." In Det tredje språket. Multimodale studier av interkulturell kommunikasjon $i$ kunst, skole og samfunnsliv, ed. by Engebretsen, Martin, 196-211. Kristiansand: Portal. 